\title{
DINAMIZAÇÃO E MEDIAÇÃO NA BIBLIOTECA ESCOLAR: Potencialidades da Leitura Literária
}

\begin{abstract}
Resumo
A biblioteca escolar se constitui em um espaço privilegiado para democratização da leitura. Aborda as potencialidades dessa instituição, que se encontram condicionadas à organização e à dinamização de estratégias e ações de mediação. A leitura literária promove uma nova dinâmica, pois aproveita e potencializa a curiosidade, a inquietude, o desejo e a criatividade dos leitores. Essas estratégias e ações rompem com a precariedade em que se encontra esta instituição e com as práticas passivas, utilitaristas e escolarizadas historicamente desenvolvidas no ambiente escolar.
\end{abstract}

Palavras-chave

Biblioteca escolar. Dinamização da leitura. Leitura literária. Mediação de leitura.

\section{INTRODUÇÃO}

A mediação de leitura é um processo complexo e, por conseguinte, pode ser abordada a partir de diversas perspectivas que se intercruzam, mas que, no seu conjunto, têm como finalidade instrumentalizar o leitor na proficiência da leitura. Desta feita, existem diversos elementos e sujeitos envolvidos, mas o campo que compreende a inter-relação biblioteca e escola parece ser bastante profícuo para reflexões, debates e avanços em busca da concretização desse objetivo, notadamente, por intermédio da democratização da leitura.

Com efeito, a biblioteca escolar se apresenta como espaço dedicado ao acesso às diversas fontes de informação, objetivando contribuir com os processos de democratização da informação e de formação de alunos e professores leitores. Ela se apresenta como ambiente privilegiado para a mediação da leitura em seus diversos matizes porque constitui ambiente onde os diferentes elementos se encontram presentes e os diversos sujeitos podem atuar de forma articulada e colaborativa.

Diante da finalidade e das potencialidades dessa instituição, há de se considerar a necessidade de organização e dinamização de modo a condicionar o estabelecimento de estratégias e o desenvolvimento de ações capazes de promover a mediação da leitura na escola. Ocorre que a realidade da biblioteca escolar brasileira, sobretudo nas escolas públicas, parece não contribuir efetivamente com os processos de mediação que a caracterizam.

$\mathrm{Na}$ presente intervenção, procura-se problematizar e provocar discussões, no contexto mais amplo do Programa Nacional de 
Biblioteca na Escola (PNBE) ${ }^{1}$, acerca do processo de mediação da leitura, considerando, a um só tempo, as condições em que se encontram a biblioteca escolar no Brasil e as potencialidades do livro de literatura infantil dentro de uma perspectiva de reverter o quadro de precariedade de que padece historicamente essa instituição.

A proposta, de forma mais precisa, é refletir sobre os processos de dinamização e mediação na biblioteca escolar no campo da leitura da literatura infantil. O pressuposto é o de que a prática da leitura literária, por suas especificidades, requer uma série de condições que são constitutivas da dinamização e da mediação nesse espaço escolar. Trata-se de analisar a mediação a partir da inter-relação necessária entre biblioteca e escola.

O fato é que uma ambiência bem planejada e organizada possibilita a articulação de diversas atividades e ações que, em essência, se apresentam como promoção da leitura do livro literário. A biblioteca na situação em que se encontra é dispensável e, portanto, pode ser substituída por salas ou cantinhos de leitura e seus similares. Insiste-se, contudo, em que este é um momento oportuno para compreender que, para além de programas transitórios de governos, os acervos enviados para as escolas via PNBE se apresentam como vetores para iniciar um processo de reversão dessa situação que se arrasta, nos diversos cantos do país.

Se, por um lado, planejar e organizar acervos ou, mais amplamente, bibliotecas escolares parece não se apresentar como suficiente para contornar a situação em que se encontra a leitura no sistema educacional brasileiro, por outro, a leitura literária na sala de aula, por vezes descontínua e desarticulada de outras atividades escolares, também pode não representar considerável contribuição para a democratização da leitura. A biblioteca escolar se apresenta como ponto de integração da leitura realizada nas diversas salas de aula.

1 Instituído em 1997, no âmbito do Fundo Nacional do Desenvolvimento da Educação (FNDE), em parceria com a Secretaria da Educação Básica do Ministério da Educação (SEB/MEC), o PNBE tem como objetivo principal democratizar o acesso a obras de literatura para crianças e jovens, e a materiais de pesquisa e de referência a professores e alunos das escolas públicas brasileiras (BRASIL, 2008).

\section{BIBLIOTECA ESCOLAR E LEITURA LITERÁRIA: AMBIENTES DA MEDIAÇÃO}

A biblioteca escolar corresponde, nas palavras de Silva e Bortolin (2006), à base de formação de leitores; porém — presa ainda ao submundo da escola brasileira, na medida em que seu entendimento permanece exclusivamente restrito ao discurso ou, nos casos em que efetivamente existe - ela funciona de forma insatisfatória.

O fato é que, muitas vezes, a denominação de biblioteca escolar é utilizada, sem nenhum critério, para designar tão somente uma estante com alguns livros, localizada em algum recanto da escola. Ademais, ela é vista como uma instituição estática e desarticulada dos demais elementos que compõem o sistema educacional brasileiro.

De fato, quando existem na escola espaços denominados bibliotecas, estes não passam, na maioria dos casos, de verdadeiros depósitos de livros ou, o que é pior, de objetos de natureza variada, que não estão sendo empregados no momento, seja por estarem danificados, seja por terem perdido sua utilidade (SILVA, W. C., 2003, p. 15).

Para além desse estado de coisa, a biblioteca escolar no espaço da mediação de leitura deve ser vista necessariamente como centro de aprendizagem integrado às diversas atividades que compõem a instituição escolar. Faz-se necessário situá-la no centro das atividades didáticas e pedagógicas visando à sua definição como um centro irradiador de uma educação dinâmica, participativa, democrática e autônoma. Para além de atender às necessidades informacionais e leitoras de alunos e professores, tradicionalmente estabelecidas, a biblioteca escolar, em sua dinâmica, propõe-se desenvolver novas necessidades, tornando-se agente de formação, desenvolvimento e aperfeiçoamento educacional e cultural.

A biblioteca escolar possibilita a ruptura com as limitações do ensino centrado nos discursos do professor e do livro didático. 
Ela passa a ser um instrumento pedagógicocultural, focado em um processo de mediação que visa, em última análise, a instrumentalizar o leitor na proficiência da leitura.

Para tanto, é preciso superar uma série de dificuldades que vão desde a concepção de biblioteca escolar ao seu efetivo funcionamento. Nesse conjunto, Silva e Bortolin (2006) destacam a já conhecida e indevida ocupação, pelos professores, do espaço do bibliotecário na escola, fato a que se adiciona o despreparo pedagógico desse profissional para atuar junto às atividades pedagógicas. São questões críticas que estão além de corporativismo ou acusações recíprocas.

Considera-se, pois, que, “[...] no processo de mediação de leitura um fator de fundamental importância é o espaço/ambiente que privilegie as crianças, leitoras em formação, bem como a atuação comprometida dos profissionais pela mediação" (MARTINS, 2006, p. 61). Além disso, o compromisso com uma escola de qualidade que tenha a formação educacional e cultural como meta coloca tais profissionais em um mesmo projeto que envida a soma de esforços em torno da mediação de informação, leitura e lazer. Não se pode perder de vista, contudo, que, para a biblioteca escolar se apresentar efetivamente como um espaço de mediação, ela precisa preencher condições mínimas que possibilitem a organização e o desenvolvimento de uma série de estratégias e ações que promovam a prática da leitura literária.

[...] a mediação da leitura é uma tarefa de fundamental importância e [...] exige formação que englobe aspectos científicos e educacionais, além de compromisso e disposição para que os projetos da biblioteca não se tornem insipientes e descontínuos; nem tampoucos alheios às discussões pedagógicas da escola (SILVA; BORTOLIN, 2006, p. 14).

Assim, a biblioteca escolar deve ser concebida numa perspectiva de ambiência própria da dinâmica da leitura do livro literário, que, complementarmente, apresenta uma série de elementos que, a um só tempo, potencializa tanto a dinamização dessa instituição social quanto o incentivo à leitura literária.

Com efeito, o livro de literatura rompe com a noção de biblioteca escolar como o espaço destinado a ser o guardião do livro, o responsável pelo castigo e, na melhor das hipóteses, o templo para os interessados na pesquisa escolar, os quais, muitas vezes, se restringem a copiar algumas páginas de livros didáticos e/ou enciclopédias. Essa suposta facilidade foi ampliada com a inserção das novas tecnologias de informação e comunicação, principalmente da internet, no ambiente de pesquisa escolar.

A leitura literária promove uma nova dinâmica no ambiente da biblioteca escolar, uma vez que esta aproveita e potencializa a curiosidade, a inquietude, o desejo e a criatividade das crianças. Essa perspectiva leitora rompe, em certa medida, com a visão simplificada, passiva, utilitarista e escolarizada da biblioteca vista como uma extensão da sala de aula e, por conseguinte, destinada à pesquisa, à leitura e às demais atividades didáticas vinculadas apenas a uma prática avaliativa. Frequentar a biblioteca passa a ser, ao contrário, um ato volitivo em um ambiente ativo de integração e escolhas.

Com efeito, "[...] a literatura é capaz de criar tensões em nós mesmos e suscitar intuições acerca da vida humana. [...] a leitura — principalmente a leitura do texto literário pode se constituir num fator de liberdade e transformação dos homens" (SILVA, E. T., 2003, p. 21).

Nesse mesmo horizonte, Yunes e Pondé (1988) compreendem que a leitura do texto literário se apresenta como instrumento de conscientização, pois possibilita a expansão da capacidade e do interesse de compreender e lidar com o mundo, a ciência, a cultura e o trabalho. Se a leitura tem como centralidade o discurso sobre a vida, considerada essa em sua totalidade e complexidade, a leitura especificamente literária tem na sua base, como condição própria, a fruição estética do texto.

[...] mediar à leitura na escola envolve um conhecimento prévio dos processos de ensino, a concepção de educação, o projeto educativo cultural da escola, a concepção de leitura e da 
prática pedagógica, a concepção de cultura infantil, os espaços disponíveis para o educando ler, bem como peculiaridades da pessoa que está à frente desta ação (MARTINS, 2006, p. 57).

Ademais, no processo de mediação, é importante que o medidor considere os elementos que fundamentaram a seleção dos textos que compõem a leitura. É justamente nesse sentido que o PNBE estabeleceu três grandes categorias de critérios de seleção de obras na constituição do acervo, a saber, a qualidade do texto, a adequação temática e o projeto gráfico.

No que se refere à qualidade do texto literário, consideraram-se basicamente as possibilidades de ampliação do repertório linguístico, a promoção da fruição estética e o favorecimento da leitura autônoma. $\mathrm{Na}$ definição da adequação temática, observaram-se o interesse do público-alvo (crianças, jovens, adultos e idosos) $)^{2}$, a motivação da leitura, o incentivo à leitura, as expectativas dos leitores e as possibilidades de ampliação do universo de referência. E, já no que concerne ao projeto gráfico, contemplaram-se adequação e expressividade, criatividade, tipos gráficos, relação entre texto e ilustração, entre outros (BRASIL, 2008).

\section{A LEITURA LITERÁRIA NA BIBLIOTECA ESTRATÉGIAS DINAMIZAÇÃO}

A leitura literária, em função de suas especificidades, deve ser refletida e praticada dentro de uma perspectiva ampla, que tem como pano de fundo o conjunto de estratégias e ações de organização e dinamização da biblioteca escolar considerada ambiente profícuo ao processo de mediação.

É forçoso compreender, com base em Silva, E. T. (2003), que o acesso ao livro não garante, por si só e necessariamente, o surgimento da leitura como experiência de prazer e de conhecimento objetivo da

2 Os jovens, adultos e idosos compõem o público leitor que faz parte da Educação de Jovens e Adultos (EJA). realidade. Trata-se, antes, de trabalhar os diversos elementos que compõem os critérios de seleção de formação e desenvolvimento dessas coleções, acima apontados.

Além do planejamento escolar conjunto que estabeleça estratégias e promova ações de mediação de leitura, a biblioteca deve apresentar-se como um ambiente aprazível em todos os sentidos, cobrindo não somente uma boa coleção, mas também espaço físico, mobiliário, iluminação, decoração, ventilação e comunicação adequados, entre outros. Isso implica, em última análise, que a instituição precisa primeiramente considerar as especificidades da obra literária e desenvolver atividades que dão conta de suas características apontadas por Pinto (2012), notadamente, o caráter artístico, a literalidade e a polissemia.

A leitura literária amplia os horizontes da biblioteca escolar, na medida em que promove a leitura vinculada ao lúdico, ao prazer, à curiosidade, à imaginação, à fantasia e à criatividade, e, por outro lado, desvinculada da necessidade de realização de trabalhos escolares. A biblioteca escolar, nessa perspectiva, passa a ser o centro irradiador e aglutinador das diversas atividades que compõem o processo de mediação. No universo de possibilidades, podem-se destacar, conforme se lê em Garcia (1998), a hora do conto, a roda de leitura, as feiras de livros, as mostras literárias, a contação e a recontação de histórias, os concursos de poesia, os diários eletrônicos de leitura, os recitais literários, entre outros.

Esse conjunto de ações tem por base o entendimento de Ramos, Panozzo e Zanolla (2008), que consideram a leitura do texto literário como constantes processos de reconstituição do universo simbólico e das vivências pessoais de cada leitor. Essa leitura exige, além da habilidade do domínio do código linguístico, outras particulares que privilegiem sua literariedade e seu papel humanizador, tais como a natureza, a linguagem, os vazios e a polissemia do texto. $\mathrm{O}$ processo de mediação se dá justamente como auxilio ao leitor na percepção e na exploração das diferentes possibilidades de leitura do texto literário. 
Pinto (2012) acrescenta que a mediação da leitura por intermédio da literatura, sobretudo a infantil, tem como fundamento a leitura como arte, uma vez que atua sobre a mente e o espírito, estimula a vivência de outros contextos e tempos, e transita entre o real e o imaginário. No conjunto de estratégias de leitura, é importante considerar o papel da ilustração, que, ao mesmo tempo, estabelece relação íntima com a palavra e, principalmente, na ausência desta, passa a ser muitas vezes o próprio texto.

\section{CONSIDERAÇÕES FINAIS}

Considera-se que o PNBE é uma tentativa de suprir, em certa medida, as lacunas existentes nesse espaço de intermediação de diversas práticas educacionais e culturais. Por outro lado, é importante não perder de vista que - embora tenha havido esforços, sobretudo aqueles vindos do governo federal, de acordo com um conjunto de políticas educacionais - não vem sendo dispensada à biblioteca escolar, apesar de tudo isso, a devida atenção.

A própria proposta do PNBE, principalmente a constituição de seus acervos e o impulso para a democratização da leitura, pode ser motivadora de um redirecionamento da visão que se tem da biblioteca escolar e, principalmente, das práticas emergenciais e descontínuas pedagógicas e culturais que vêm sendo historicamente desenvolvidas em torno dela.

Não obstante a apresentação de indicadores formais, é forçoso reconhecer que o PNBE não empreendeu os ajustes necessários para que se desse a aproximação das classes de professor e bibliotecário. Esse diálogo é não somente importante como imprescindível para a devida dinamização e o efetivo funcionamento dessa instituição, que, por natureza, se apresenta como ambiente de mediação de informação, leitura, cultura e lazer.

Além disso, a aproximação da sala de aula e da biblioteca, por intermédio do PNBE, decorre também do solo fértil que esta última proporciona à sua própria dinamização, uma vez que a leitura literária rompe com as práticas ordinárias de alfabetização, escolarização da leitura e reforço escolar, dando-lhes uma nova força, por intermédio de diversas estratégias e ações, tais como a hora do conto, as mostras literárias, a contação de histórias, os diários eletrônicos de leitura, os recitais, entre outras.

Parece existir um desconhecimento das potencialidades de integração entre a biblioteca e a escola, fato que resulta na ausência do trabalho conjunto de professores e bibliotecários. Esse distanciamento, mais do que nunca, precisa ser superado, principalmente pela necessidade da efetividade do disposto na Lei $\mathrm{n}^{\circ}$. 12.244, de 24 de maio de 2010, sobre a implantação de bibliotecas escolares em todas as instituições de ensino do país (BRASIL, 2010).

Por fim, é importante considerar que, nessa perspectiva de atuação, além de acarretar a flexibilização dos limites entre salas de aula, a biblioteca escolar é o espaço onde a atuação interdisciplinar pode se fazer presente, sobretudo entre as áreas de Biblioteconomia, Letras, Pedagogia e Psicologia.

\title{
DINAMIZATION AND MEDIATION IN THE SCHOOL LIBRARY: Potentialities of the Literary Reading
}

\begin{abstract}
School library constitutes a privileged environment for reading democratization. It deals with this institution's potentialities that are related to organization and to strategies dinamization and mediation actions. Literary reading promotes a new dynamics once it potentializes the readers' curiosity, restlessness, desire and the creativity. These strategies and actions breach precariousness which this institution faces as well as the passive, utilitarian and school practices historically developed in the school environment.
\end{abstract}

Keywords

School library. Reading dinamization.Literary reading. Reading mediation. 
Artigo recebido em 20/09/2014 e aceito para publicação em 29/09/2014

\section{REFERÊNCIAS}

BRASIL. Ministério da Educação. Programa Nacional Biblioteca na Escola (PNBE): leitura e bibliotecas nas escolas públicas brasileiras. Brasília: MEC, 2008. 130p.

BRASIL. Presidência da República. Lei $\mathbf{n}^{\mathbf{0}}$. 12.244, de 24 de maio de 2010. Dispõe sobre a universalização das bibliotecas nas instituições de ensino do país. Brasília, 2010.

GARCIA, E. G. (Org.). Biblioteca escolar: estrutura e funcionamento. São Paulo: Loyola, 1998.

MARTINS, E. O espaço de mediação de leitura na biblioteca escolar. In: (Org.). Fazeres cotidianos na biblioteca escolar. São Paulo: Polis, 2006. cap. 5, p. 5564.

PINTO, L.S. Mediação de leitura em sala de aula: uma experiência no $1^{\circ}$ segmento do ensino fundamental. In: CONGRESSO NACIONAL DE LINGUISTICA E FILOSOFIA, 16., 2012, Rio de Janeiro. Anais... Rio de Janeiro, 2012. p. 2272-2281.
RAMOS, F. B.; PANOZZO, N. S. P.;

ZANOLLA, T. Práticas de leitura em sala de aula. Revista ibero-americana de educación, n. 46, v. 2, 10 mayo 2008.

SILVA, E. T. Leitura na escola e na

biblioteca. 8. ed. São Paulo: Papirus, 2003.

SILVA, J. R.; BORTOLIN, S. Reflexões sobre a leitura e a biblioteca escolar. In:

(Org.). Fazeres cotidianos na biblioteca escolar. São Paulo: Polis, 2006. cap. 1, p. 1119.

SILVA, W. C. A miséria da biblioteca escolar. 3. ed. São Paulo: Cortez, 2003.

YUNES, E.; PONDÉ, G. Leitura e leituras da literatura infantil. São Paulo: FTD, 1988. 